\title{
Role of Enterprise Excellence Initiative
}

\author{
DHIRENDRA KUMAR \\ 909 Capability Dr. Raleigh, NC 27695 \\ North Carolina State University, USA \\ Tel: 919-515-5439 E-mail: Dhirendra_Kumar@ncsu.edu
}

\begin{abstract}
The Enterprise Excellence (EE) philosophy is a holistic model for leading an enterprise to total excellence by focusing on the needs of the customer whether within the state, the nation, and the world. The rate of change in today's competitive world is constantly increasing. Competition is forcing businesses to be well funded and at the same time, customers are becoming unpredictable.

These requirements are creating practical problems of the modern world and the applied research initiative will solve these problems. For example, applied research from enterprise point of view will focus on uncovering what needs are not being met within a targeted market and use that information to begin formulating products or services (including existing products) that will be attractive and desirable. Therefore, to catalyze the transformation of economies tied to these industries, the Enterprise Excellence Initiative (EEI) must be nurtured and developed.
\end{abstract}

Keywords: Applied research initiative, Enterprise change management, Enterprise excellence initiative, Lean advancement initiative, Operational excellence

\section{Introduction}

The Enterprise Excellence Initiative (EEI) is a holistic model for leading an enterprise to total excellence by focusing on the needs of the customer whether within the state, the nation, and the world. In the state of North Carolina, there are traditional industries (furniture, textile, tobacco, etc.), as well as leading edge industries (aerospace, information technology, pharmaceutical, health care, government, etc.), but businesses in all kinds of industries are innovating and trying to grow/survive in a global economy. The rate of change in today's competitive world is constantly increasing. Competition is forcing businesses to be well funded and at the same time, customers are becoming unpredictable. These constantly changing hurdles are creating unfamiliar condition for leadership. For example, a furniture manufacturing company was profitable 12 months ago, but lost money last quarter. The leadership is afraid that the work would be outsourced to China.

Some of these industries make significant and growing contributions to North Carolina's economy, and the global economy is creating new requirements in the areas of people, market, and profit for these industries to compete and grow/survive.

People:

People are the most important assets. These businesses will not be successful without people resource, but the people resource has to adjust according to business requirements to satisfy customers. The word "adjustment" in technical terms is known as "Cultural change." The following are some of the commonly known scenarios where cultural change is required for businesses to stay successful and compete in the marketplace:

- Business survival is an issue

- Business leadership goal is to stay number one in industry or wants to be number one

- Safety, security, natural disaster and/or environmental issues

- Business growth and professional development

Market:

In a product-market growth relationship, marketers have to consider four ways of relationship between product and market via present and or new markets, existing and/or new products. So, it can be written as follows:

- $\quad$ Market - Present and/or new

- $\quad$ Product - Existing and/or new

The risk element increases as businesses move further away from known markets and existing products. Thus, new products and new markets typically create greater risk of penetration than the existing products in present markets. New product development may require new skills, new techniques, and new facilities. These changes 
would require physical and organizational changes in the business structure which could represent a clear break with the past business experience.

Profit:

All the organizations, except non-profit organizations, are in the business of making money. It takes resources (capital, people, facility, technology, etc.) and market to make money (sales/revenue, margin/profit). Any business strategy that does not consider the financial condition of the business can be a quick passage to bankruptcy. Business leaders and applied researchers must understand the products/services the business provides to customers and their impact on the bottom line.

These requirements are creating practical problems of the modern world and the applied research initiative will solve these problems. For example, applied research from enterprise point of view will focus on uncovering what needs are not being met within a targeted market and use that information to begin formulating products or services that will be attractive and desirable. This simple and systematized approach may also be applied to existing products as well, leading to the development of new and improved product of currently offered product. Therefore, there is a great need for an organization to conduct applied research to support these industries.

\section{Literature Survey}

Lean Advancement Initiative (LAI, 2009) at Massachusetts Institute of Technology (MIT) offers organizational members from industry, government, and academia the newest and best thinking, products, and tools related to lean enterprise architecting and transformation. LAI is a unique applied research consortium that provides a neutral forum for sharing research findings, lessons learned, and best practices.

Montgomery (2010) has recognized that students from different major fields such as engineering, statistics and business should be educated all aspects of Lean Six Sigma to achieve enterprise excellence. He is also recognizing that more wide spread education about the approach among employees is required, but additional tools are needed to achieve enterprise excellence.

Prahalad and Hamel (1990) coined the term core competencies and identified it as the collective learning and coordination skills behind the firm's product lines. They made the case that core competencies are the source of competitive advantage and enable the firm to introduce an array of new products and services.

Although it has been widely accepted that core competency is the source of sustainable competitive advantage, its source and logic structure is being disputed and explored. Many researchers have presented different definitions from their study viewpoint as presented below:

- $\quad$ The knowledge view (Leonard-Barton, 1992) - The knowledge view suggests that core competence is a knowledge system embodied in technology, human resource, information, and organization.

- $\quad$ The network view (Klein and Hiscocks, 1994)) - The network view advances that core competence is a network of skills and can be found out through cluster analysis of skills.

- $\quad$ The Harmony view (Sanchez et al., 1996)) - The harmony view thinks that core competence is the excellent skills of harmony deployment of assets and skills.

According to Aglipay et al. (2006), practice-based research includes many partnerships to identify and solve the complex public health problems of the $21^{\text {st }}$ century and achieve excellence. These partnerships include the traditional public health agencies, universities, and communities, as well as new partnerships between researchers and communities to develop approaches and solutions.

Center for Operational Excellence (COE) (2008) was created in the Fisher College of Business at the Ohio State University. The COE is a unique partnership of business leaders and educators who share a common ideal of achieving competitive advantage and excellence in operations management through education, research and networking. A master level degree program is offered called "Master of Business Operational Excellence."

Master in Management: Operational Excellence program is offered at Vincent College. No applied research type of project requirements in this degreed program.

We assume that enterprise excellence is something that we can define, analyze, plan for, and then maintain it forever. Unfortunately, with each change in business, the leadership team has to understand its impact, develop and analyze solution(s), and distinguish a good idea from a bad one. Leadership must also recognize that excellence is a continuous (never ending) process. 


\section{Role of Faculty (Academic Staff), Students and Industrial Extension Service in Applied Research Initiative for Enterprise Excellence}

The department of Industrial Extension Service (IES) (Note 1) at North Carolina State University (NCSU) is providing engineering and business services to industries throughout the state of North Carolina and producing measurable economic impact. Literature validates that EEI is a collaborative effort and IES is an excellent connecting link between industries and the university resources such as faculty and students. So, IES led the activities of applied research where the faculty and students from various colleges (Textile, Management, and Education to just name a few) and business leaders participated.

Students (undergraduate and graduate) are involved in many IES projects (engineering and business). These students work on "Enterprise Excellence" programs to improve supply chain (material management), throughput, cash flow, and strategic planning. This has created a win-win-win situation: Clients save money compared to projects conducted either by their employees or third party professionals; students benefit from hands-on experience in industrial, commercial, and healthcare settings; and IES can serve more clients by virtue of having a much larger pool of available student talent.

Additionally, students get the opportunity to apply their classroom and laboratory lessons in real-world applications. So, students will also be involved in the applied research projects and gain research experience. This will provide them additional training and education before joining the business environment. Therefore, to catalyze the transformation of economies tied to these industries, the Enterprise Excellence Initiative (EEI) was nurtured and developed in the IES department. The initiative has enhanced the ability of organizations to compete globally and contributing to the state's economic development.

The initiative would work to ensure North Carolina's competitive advantage as a leader in these important industries. Therefore, the Mission, Vision, and the Values of the Institute were developed.

\subsection{Mission}

To support enterprise transformation through multidisciplinary applied research and outreach focused on the triple (People, Market, and Profit) bottom line.

\subsection{Vision}

1. Bring multidisciplinary expertise to provide

- Holistic student learning

- $\quad$ Systematic solutions for industry

- $\quad$ Peer-review research;

2. Align the program with applied research, business and engineering services, and teaching; and

3. IES will improve outreach to statewide businesses and industries with measurable impact.

3.3 Values

1. Integrate a multidisciplinary approach with other NCSU Departments to support the mission.

2. Encourage and support applied research and scholarly activities to advance the frontier of knowledge in enterprise excellence.

3. Provide unique opportunities to engage with enterprises and partners to solve problems and share organizational transformation experiences.

4. Provide innovative enterprise transformation products, tools, and methodologies.

5. Offer a portfolio of thought provoking knowledge exchange events and meetings.

6. Create opportunities to receive grants and contracts.

\section{The Enterprise Excellence Initiative at NCSU}

The EEI together with its educational network offers innovative thinking and best practices to organizational members from business, government, and academia in the form of products, and tools related to enterprise excellence. EEI is be a unique applied research consortium that provides a neutral forum for sharing research findings, lessons learned, and best practices.

The conceptual flow chart to conduct the applied research is presented in Figure 1. Two network groups (Academic staff and Enterprises) actively participating in the applied research program. Academic staff also provides students (as available) to participate in the selected platforms (research topics, products, and tools). For 
example, some of the platform topics are Lean Culture, Supply Chain, and Cultural Change. The enterprise leaders have to answer certain questions to understand what it would take to achieve enterprise excellence. A list of selected questions is presented below. These questions generate research topics at the enterprise level. The EEI leadership holds periodic meetings to discuss these topics with enterprise leaders of member (participating) organizations and select the most demanding research projects for the identified platforms and assign the resources. The staff of EEI will mentor the enterprise excellence program (utilizing applied research results) at client/member site with the support/participation of IES.

In order to achieve enterprise excellence, the enterprise leadership needs to ask the following five questions:

1. Where is currently enterprise within larger context?

2. What would it take to achieve the Enterprise Excellence?

3. How to develop most effective strategies and tactics to achieve the future state of the enterprise?

4. How to manage the enterprise change process?

5. What metrics to use to evaluate the progress?

These questions do help to follow the research process as presented in Figure 2.

Conceptual relationship among questions, activities, and resources is presented in Figure 3. The major participants in the research projects are EEI staff, interested (participating) organizations, and academic staff and students. Project activities are divided into five groups:

1. Enterprise analysis;

2. Enterprise product design and development;

3. Enterprise systems engineering;

4. Enterprise change management; and

5. Measurement metrics

These activities are not in silos. All the participating resources would need a true partnership to support the applied research programs to develop/modify products.

Therefore, the EEI is to:

- $\quad$ Address enterprise processes and issues;

- Develop and deploy applied research products into practice;

- Create powerful partnership between academia and enterprises;

- Support enterprise excellence programs at organizations;

- Learn from communities of practice and benchmarking;

- Communicate/educate organizations from case studies;

- Become engine for intellectual capital through transformation products; and

- Publish results through technical papers, articles, and books.

\section{Case Study - Raleigh Lions Clinic for the Blind (RLCB)}

The Enterprise Excellence Initiative model was tested at Raleigh Lions Clinic for the Blind (RLCB) and the test results are presented in this case study.

Business Status and Leadership Goals:

The Raleigh Lions Clinic produces highly specialized products based on military specifications. They supply six military Defense Supply Centers nationwide and act as a distribution center for the federal General Service Administration. Therefore, their customers expect nothing less than the designated order, right down to the gauge of thread used in sewn components. None of these parameters are especially noteworthy, until you take into account that most of those producing said items are blind.

Operations site was utilizing over 200,000 $\mathrm{ft}^{2}$ facility. Material (raw, W-I-P and finished) was stored everywhere. One new product RLCB had to bring in production, but hardly any manufacturing site planning, layout and process testing was done. This product was expected to be approximately $1 / 4^{\text {th }}$ of the total future business revenue. There were numerous issues with the existing products, such as difficult to meet customer demand, excessive material handling, process flow, etc.

The clinic leadership was looking for significant improvement in material flow, throughput, inventory reduction, higher manufacturing facility utilization, and higher revenue, profitability and cash flow. Leadership was expecting enterprise excellence to compete and grow.

Business analysis: 
In order to achieve enterprise excellence, the enterprise leadership had to participate in the business analysis and develop a growth strategy.

The first question was, "Where is currently enterprise within larger context?" In simple and non-technical terms, leadership presented their business status and also the expected goals in the previous section. So, to develop a competitive strategy, leadership needs to develop a plan and a growth strategy to compete and grow. In order to develop a plan and a growth strategy, leadership needs to analyze the competitive forces:

- $\quad$ Threat of new entrant: Five elements were analyzed - new capacity, market share, price, competition and profit margin. RLCB's core competency of training an average blind person into a skilled worker became an overriding element over the above listed elements. Prahalad and Hamel (1990) made the case that core competencies are the source of competitive advantage and enable the firm to introduce an array of new products and services. So, the training of blind workforce is providing the competitive advantage to RLCB.

- Threat of substitute product: Most of these products were designed by government agencies for their employees use. If any third party designs a better product and the government accepts the design then it would not hurt the RLCB in the competition.

- Bargaining power of customers: Main customer was government, so leadership was not expecting any significant change in products price, quality and delivery. In order to capture non-government market, definitely price and margin were the issues and they were improved through reducing costs.

- Bargaining power of suppliers: this was not a critical issue. RLCB was doing a great job in negotiating the material quality, delivery and price.

- Competition among existing businesses: IES did not participate in the total product cost analysis, but provided the sewing machine operator's salary and wage information at the national basis. The key element of core competency was clearly providing an advantage over competition.

Based on the investigation of the above listed elements and the impact of key business elements - people, market and profit, two-prong growth strategy was developed:

- $\quad$ To develop an overall cost leadership

- Some products were linked to differentiation (due to product complexity), so some price variation was possible on those products.

\section{Key Elements of Growth Strategy}

Based on the developed growth strategy, the two key elements for growth strategy were:

- $\quad$ Reduce cost

- Gain market share in the existing market, as well as capture new market through existing and new product(s). New product was "Molle."

Business cost was divided into three elements: material, people and facility. Purchasing group worked with suppliers and reduced material cost. People were divided into two groups: direct people (working and supporting production) and support people (supporting functions such as marketing and sales, financial, product development, and human resources). Leadership took the responsibility of optimizing the support people cost. Direct people portion in the product cost was optimized through utilizing lean and Six Sigma tools.

Concept of lean was utilized to streamline the processes which resulted in efficient use of resources (people and equipment) and the concept of Six Sigma was utilized to reduce/eliminate variation in the products quality. So, the lean and Six Sigma tools were utilized in the following activities:

- In streamlining processes: 5 products, 4 cutting tables, storage area, and receiving and shipping areas

- Reduced the facility requirements to one-half the original (from $200,000 \mathrm{ft}^{2}$ to $100,000 \mathrm{ft}^{2}$ )

- Minimized total material handling in areas such as receiving and shipping docks, warehouse and manufacturing floor

- Utilized pull concept and as close to unit flow as possible to reduce inventory

- Minimized process variation

- $\quad$ Performed strategic capacity-load analysis to meet future throughput requirements

- $\quad$ RLCB sold the facility and leased back only one-half of the building. This provided the RLCB with one time capital cash flow, but it was not included in the economic impact data (which are presented later).

Project team streamlined the manufacturing processes of all the existing products and the identified new product.

Team divided the manufacturing process into activities: value added, non-value added and waste. The value adding activities were either combined and/or improved, the non-value adding activities were minimized and the waste activities were deleted. 
Value added activities are those for which customers are willing to pay; non-value added activities are generally required by the manufacturer to stay in business; and waste activities are those for whom nobody wants to pay. Waste activities are neither required to produce nor required to support the manufacturer.

So, the overall material flow developed at the manufacturing site is presented in Figure 4 and a peak view of the production site is presented in Figure 5.

\section{The Positive Impact and the Challenges}

Defense and civilian are both very competitive markets for RLCB's products. Product prices are controlled by the market, so, RLCB had to reduce cost to make the margin. RLCB utilized Lean and Six Sigma tools which resulted in stream lining the processes, reduced material handling, and improved product quality and on-time delivery. So, the positive impacts of these initiatives were:

- $\quad$ Reduced products costs significantly,

- Gained share in the existing market, and

- Captured new markets in non-governmental businesses.

Therefore, the next step was the measurement and the elements of the measurement metrics are economic impact, jobs created and gain in the market share.

- $\quad$ Economic Impact of over $\$ 6.6$ million

- $\quad$ Total Jobs Created $=40$

- Annual revenue went up 30 percent

The elements that supported the economic impact data were:

- $\quad$ Productivity Improvement

- $\quad$ On-time Delivery

- Cost Reduction in Material, Energy, Overhead and Other areas

- Inventory Reduction

- Cost Avoidance

- Investment :

- IT

- $\quad$ Equipment

- Core Competency Equipment and Training.

The enterprise excellence initiative project moved RLCB in a better position to negotiate product contracts in the market. During deep recession of 2009, when revenue of almost every business was lowering, as well as businesses were laying-off employees, RLCB's revenue went up 30 percent and hired 40 employees. This case study validates the concept of initiating applied research for enterprise excellence.

\section{The Challenges}

This initiative created a very positive impact on RLCB, education of students and enhancing of faculty skills, but there are some challenges. The challenges identified here are based on participants' collective experience.

- Securing project: Considerable efforts are required for seeking out projects from businesses with financial support.

- Organizational complexity and diversity: Various organizations (client's business, faculty, IES and students) with different management and policy frameworks come together to achieve the research initiative successfully.

- Slow organizational and inter-organizational adaptation to change: The ways organizations define themselves, relate to the environment, approach their work, and select processes, tools and techniques all evolve more slowly than the technology around them. This is compounded when multiple groups must work together.

\section{Acknowledgements}

My gratitude is to those who have contributed in the development and testing of the applied research initiative. It is with this appreciation, I thank the following people:

Drs. Teresa Helmlinger Ratcliff, David Boulay, Deborah R. Manzo, James Daggerhart, and Lukasz Mazur from Industrial Extension Service, North Carolina State University, Raleigh, NC;

Product Specialists and graduate students, North Carolina State University, Raleigh, NC; and 
Bruce R. Roach, Chief Financial Officer and Eric Warnhoff, VP of Operations, Raleigh Lions Clinic for the Blind, Raleigh, NC.

\section{References}

Aglipay, G. S. et al. (Fall 2006). Edited by Potter, Margaret A. and B. E. Quill, Demonstrating Excellence in Practice-Based Research for Public Health, Washington, DC, Association of School of Public Health.

Center for Operational Excellence (COE). (2008). Columbus, OH, Ohio State University. [Online] Available: http://fisher.osu.edu/center/coe/

Klein, Jeremy A., and Peter G. Hiscocks. (1994). Competence-based Competition: a practical toolkit, In G. Hamel and A. Heene, (eds.) Competence-based Competition, New York, NY, John Wiley \& Sons.

Lean Advancement Initiative (LAI). (2009). Cambridge, MA, Massachusetts Institute of Technology (MIT). [Online] Available: lean@mit.edu

Leonard-Barton, D. (1992). Core Capabilities and Core Rigidities: A paradox in Managing Product Development, Strategic Management Journal, Vol. 13, Summer Special Issue, Pp 111 - 125.

Master in Management: Operational Excellence, Latrobe, PA, Saint Vincent College.

Montgomery, Douglas C. (2010). A modern framework for achieving enterprise excellence, International Journal of Lean Six Sigma, 1(1), Pp 56-65.

Prahalad, C. K., and Gary Hamel. (9May/June 1990). The Core Competence of the Corporation, Cambridge, MA, Harvard Business Review, Pp 79-81.

Sanchez, R., A. Heene and H. Thomas. (1996). Dynamics of Competence-based Competition: Theory and Practice in the New Strategic Management. Oxford, Pergaman.

\section{Short Author's Bio}

Dr. Dhirendra Kumar is Senior Engineering Extension Specialist at North Carolina State University in the USA. He has worked as an engineer, technical adviser and program manager for Outboard Marine, John Deere, Pratt and Whitney, and Pitney Bowes. Since turning to academia, Dr. Kumar has been a researcher, lecturer, senior lecturer, and a visiting and adjunct professor, holding different posts at the Universities of Iowa, Nebraska, Hartford, Central Connecticut and New Haven. He has written books, instructional manuals, and many conferences papers and is a member of a number of advisory boards and scholarship committees. In his current role he advises graduate students on industrial projects and leads projects in organizations external to his university. Dr. Kumar is also developing and taping courses for distance learning on topics such as Enterprise Growth Strategy, Business Transformation, Continuous Improvement, etc.

Note

Note 1. In 1955, the North Carolina General Assembly established the Industrial Extension Service (IES), the first of its kind in the nation, as a part of North Carolina State University's College of Engineering. They chartered IES to provide research and experimental work leading to better utilization of North Carolina's raw materials and development of its small industries. The mission expanded to include providing engineering and industrial management assistance, conducting applied research, advocating the use of technology and modern management practices, and providing continuing education to business, entrepreneurs, engineers, and local government with the goal of ensuring their continued viability in today's economy.

IES now focus on direct client assistance to meet specific needs. IES serves the entire state of North Carolina, and especially its over 10,500 manufacturing companies and their 535,000+ employees. Sixteen regional offices provide coverage across most of the state. 


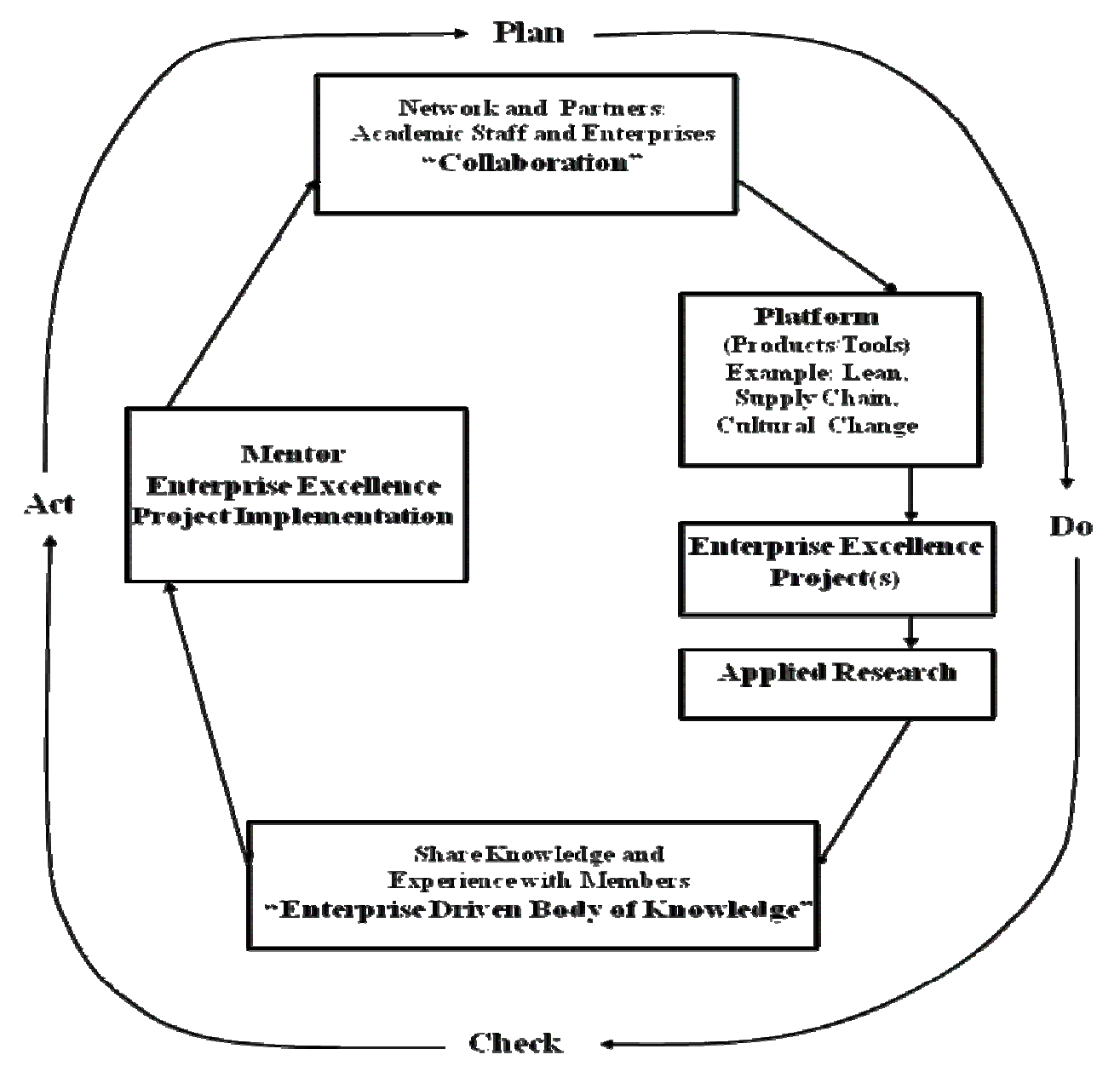

Figure 1. The Conceptual Flow Chart of Applied Research at EEI 


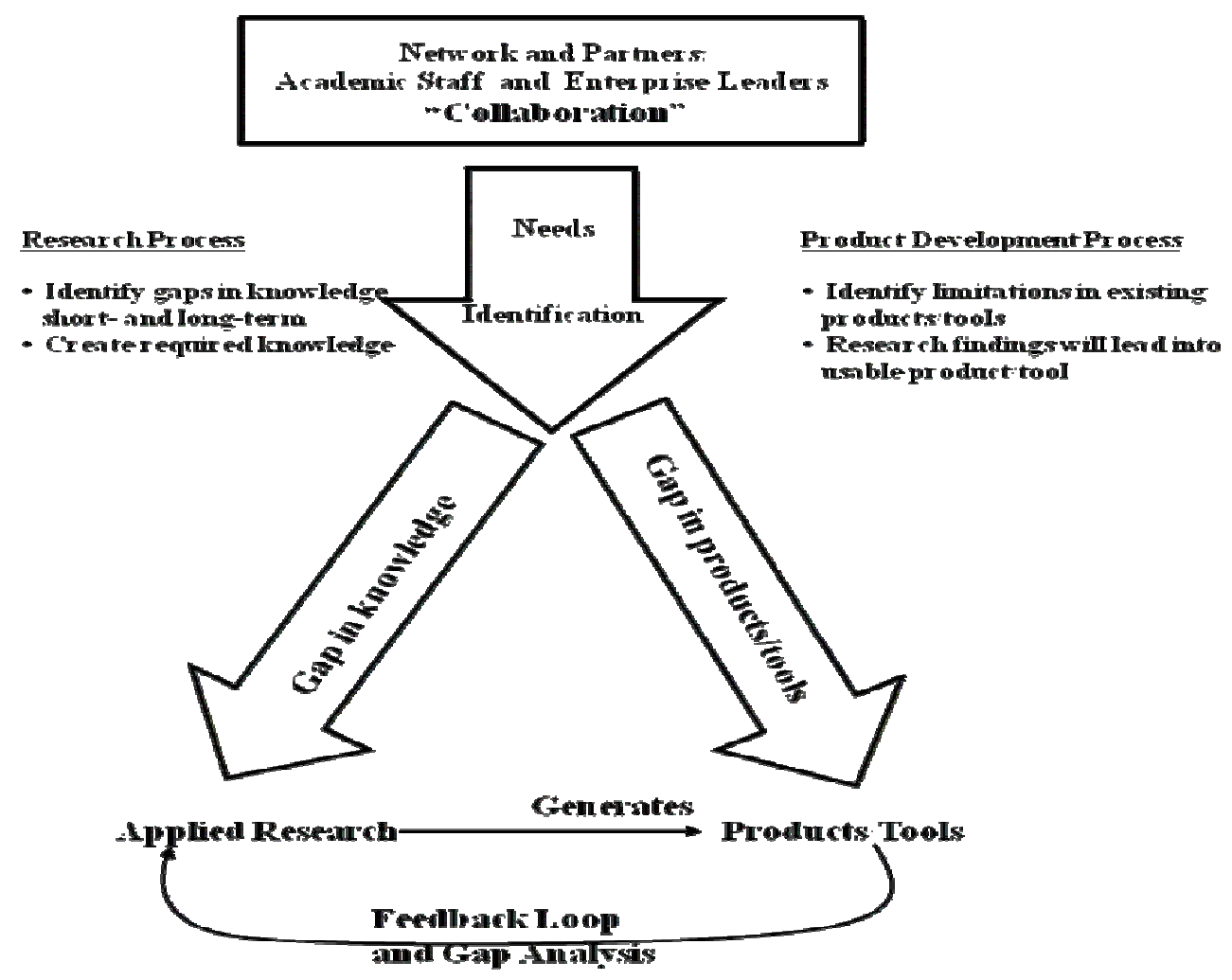

Figure 2. Enterprise Excellence's Product Development Process

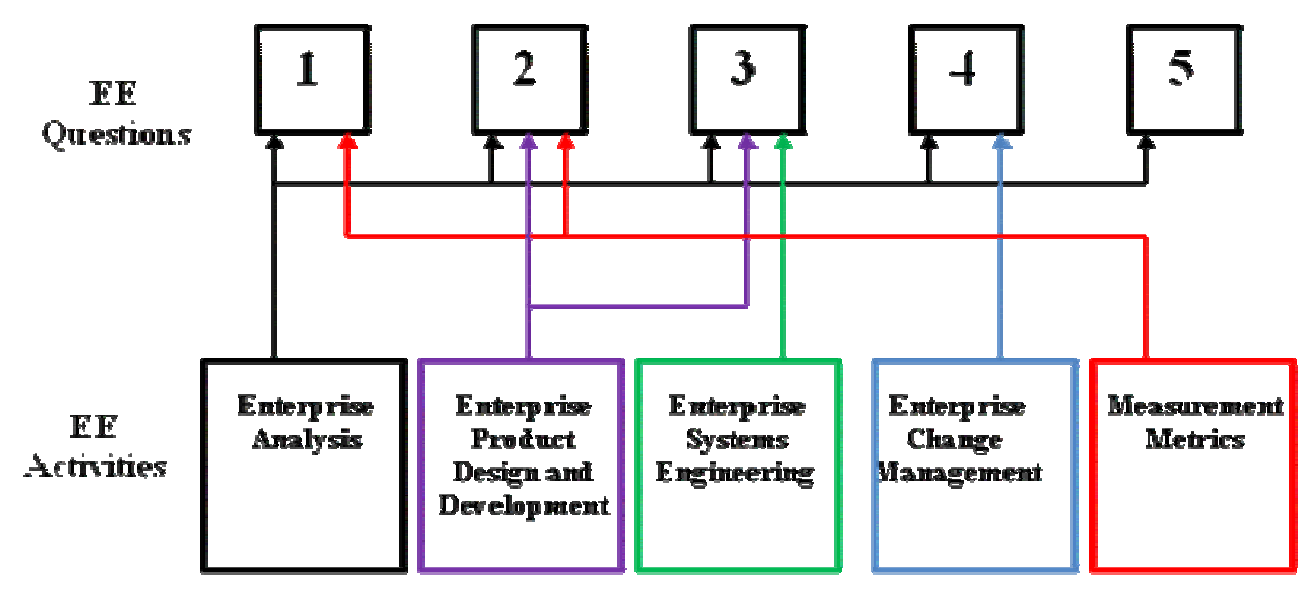

EE Particip ants. Businesses, EFI Staff, and Ac ademic Staff

- All the ahove def ined activities will not be in silos. There will be some overlap.

- Therew onld be trne parmer ship an ong identified resources.

Figure 3. Conceptual Relationship among Questions, Activities and Resources 


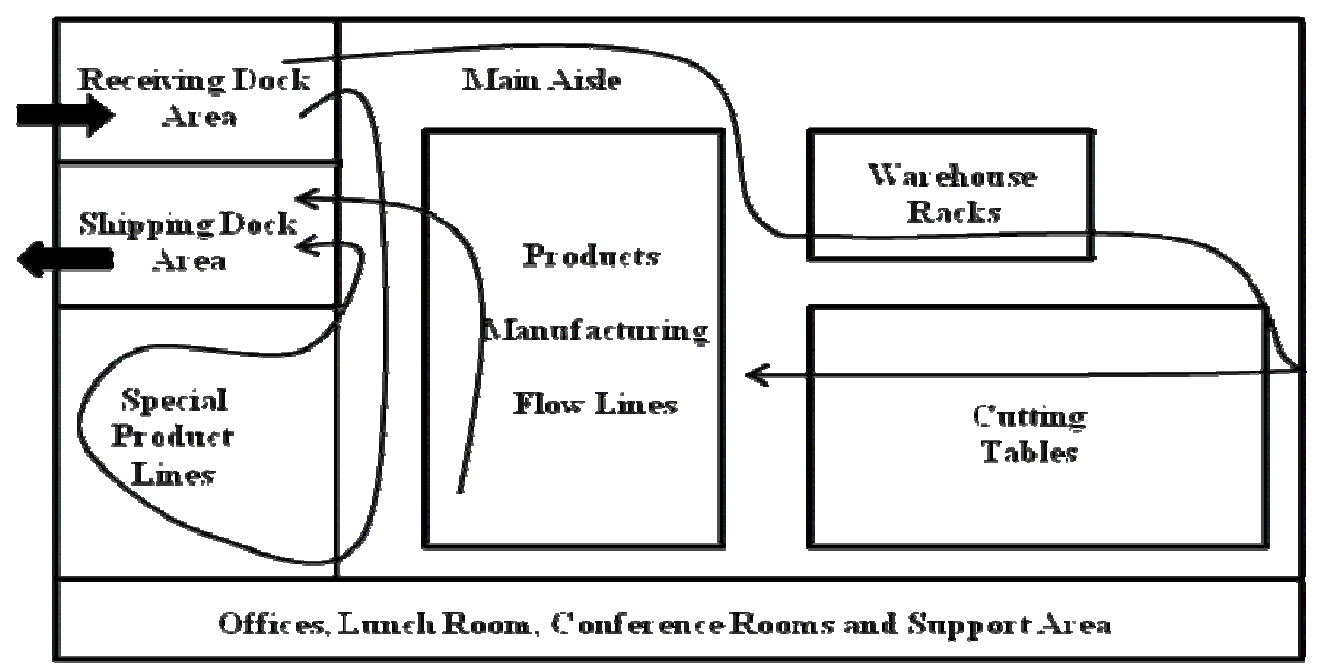

Figure 4. Overall Material Flow at RLCB

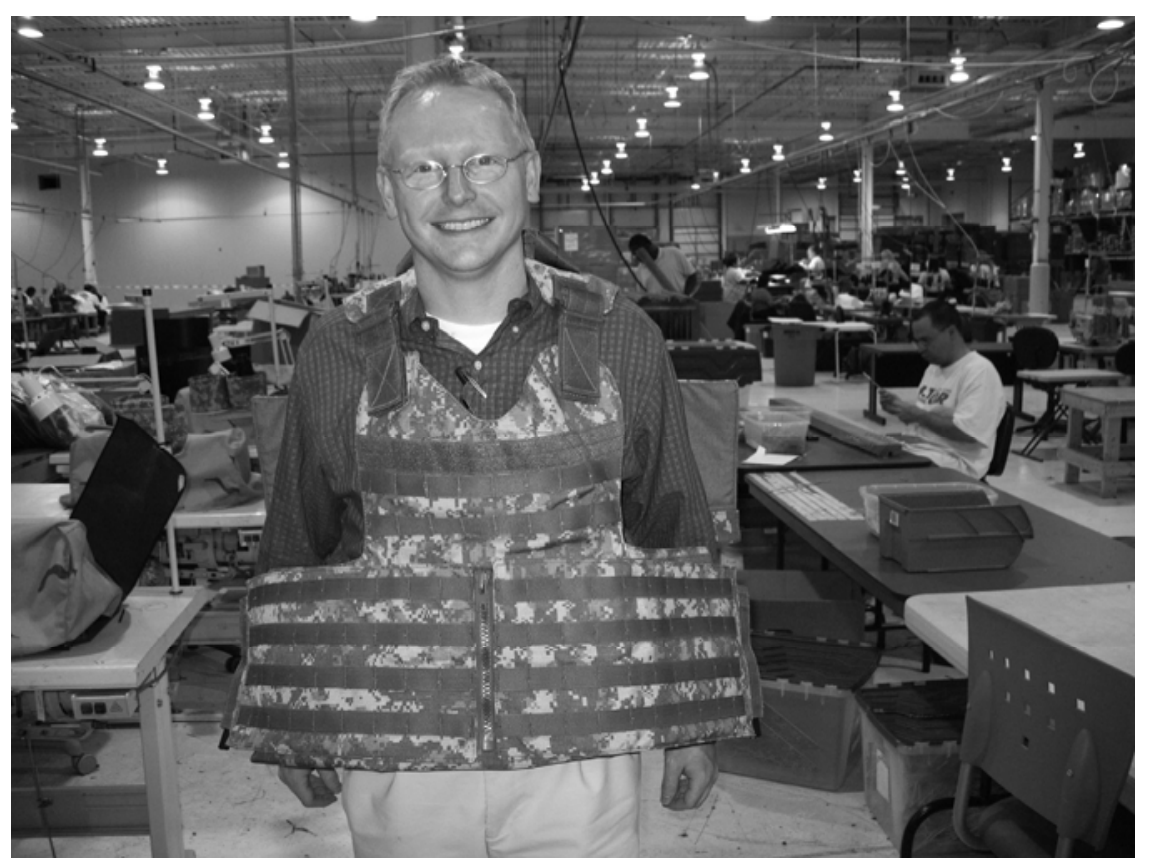

Figure 5. Peak View of Significantly Upgraded Production Site

(Eric Warnhoff, VP of Operations, models one of the many products that are produced by the visually impaired in this 100,000 square foot facility in Raleigh.) 